\title{
Outcome of Large Noninvasive Follicular Thyroid Neoplasm with Papillary-Like Nuclear Features
}

\author{
Bin Xu, Giovanni Tallini, Theresa Scognamiglio, Benjamin R. Roman, \\ R. Michael Tuttle, and Ronald A. Ghossein ${ }^{6}$
}

Background: In 2016, encapsulated follicular variant of papillary thyroid carcinoma without invasion was renamed "noninvasive follicular thyroid neoplasm with papillary-like nuclear features" (NIFTP) in order to reduce overtreatment of this indolent tumor. However, many endocrinologists remain uneasy about managing large $(\geq 4 \mathrm{~cm})$ NIFTP conservatively without radioactive iodine (RAI) therapy. The objectives of this study are to characterize the clinicopathologic characteristics and outcome of large NIFTP in order to assist therapeutic decision making.

Methods: The pathology databases of four tertiary hospitals were searched for large $(\geq 4 \mathrm{~cm})$ NIFTP. Cases with separate foci of carcinoma were excluded. Seventy-nine cases fulfilled the inclusion criteria. Among them, 56 (71\%) had at least two years of clinical follow-up (FU), and $49(62 \%)$ had four or more years of FU. The clinicopathologic characteristics were reviewed and documented by four endocrine pathologists.

Results: The median size of the NIFTP was $4.5 \mathrm{~cm}$ (range $4.0-8.0 \mathrm{~cm}$ ). The entire capsule was sampled in 50 $(63 \%)$ tumors, while in the remaining $29(37 \%)$ cases, it was submitted representatively, with a median of 2.1 blocks per centimeter of tumor examined. Large NIFTP had a female preponderance with a male:female ratio of 1:1.8, and presented at a median age of 49 years. There were no lymph node metastases at diagnosis in any of the patients, and none of the patients $(n=25)$ in whom nodal tissue was available for microscopic examination had positive findings. Twenty-six (33\%) underwent thyroid lobectomy alone, and 37 (47\%) did not receive RAI ablation. No recurrence was observed in the entire cohort, including all 32 patients with two or more years of FU who did not receive RAI therapy (median FU: 6.7 years). Among patients with four or more years of FU, all 25 individuals without RAI therapy did not recur, with a median FU of 11.2 years. Patients with a larger tumor size tended to receive postoperative RAI ablation $(p=0.001)$.

Conclusions: Similar to their small counterparts, large NIFTP appear to have an extremely low risk of recurrence (zero in this cohort), even when treated conservatively without RAI therapy. Surgical treatment alone, including lobectomy, appears to be adequate for large NIFTP.

Keywords: noninvasive follicular thyroid neoplasm with papillary-like nuclear features (NIFTP), follicular variant, papillary thyroid carcinoma, radioactive iodine

\section{Introduction}

T HYROID CARCINOMA is the cancer with the largest increase of incidence in the United States in the past decade, with 62,980 new cases diagnosed annually (1). This increase is mostly attributed to a sharp rise in follicular variant of papillary thyroid carcinomas (FVPTC) and papillary microcarcinomas (2). Regardless of tumor size, the proportion of papillary carcinomas with follicular growth pattern (i.e., FVPTC and follicular variants of papillary micro- carcinomas) among all papillary thyroid carcinomas (PTC) has tripled from $18 \%$ to $57 \%$ in the past four decades, surpassing the papillary (classical or usual) pattern and becoming the most common architectural pattern encountered in PTC (2).

Histologically, FVPTC is characterized by an almost exclusive follicular growth pattern and the presence of nuclear features of PTC, for example nuclear enlargement, nuclear membrane irregularity, and chromatin clearing and margination $(3,4)$. Recent molecular studies, including The

\footnotetext{
${ }^{1}$ Department of Pathology, Sunnybrook Health Sciences Centre, Toronto, Canada.

${ }^{2}$ Department of Pathology, Bologna University School of Medicine, Bologna, Italy.

${ }^{3}$ Department of Pathology, Cornell University, New York, New York.

Departments of ${ }^{4}$ Surgery, ${ }^{5}$ Medicine, and ${ }^{6}$ Pathology, Memorial Sloan Kettering Cancer Center, New York, New York.
} 
Cancer Genomic Atlas (TCGA) of PTC, have shown that FVPTC are often $R A S$ mutated and carry a molecular signature resembling the follicular adenoma (FA)/follicular carcinoma group of tumors and are distinctly different from the classical variant of PTC that are often $B R A F$ mutated (57). The encapsulated noninvasive form of FVPTC in particular has been shown to follow an extremely indolent clinical course, with a negligible risk of lymph node metastasis and recurrence when completely resected (6). Realizing the epidemic of diagnoses, unique molecular signatures, and highly indolent nature of the encapsulated noninvasive FVPTC, a working group of 28 internationally renowned endocrine experts critically reexamined this entity in 2014 (3). Among the 108 cases of encapsulated noninvasive FVPTC with no radioactive iodine (RAI) treatment and with at least 10 years of follow-up (FU), there was not a single recurrence. Hence, the consensus group advocated for a nomenclature revision of this entity to "noninvasive follicular thyroid neoplasm with papillary-like nuclear features" (NIFTP), in an effort to reduce overtreatment by eliminating the term "carcinoma" (3).

Prior to the introduction of the NIFTP term, large encapsulated noninvasive FVPTC were staged as pT3 and clinical stage III in patients $>45$ years of age using the 7 th edition of the American Joint Committee on Cancer (AJCC) staging manual (8). According to the 2015 American Thyroid Association (ATA) guidelines, postoperative RAI should be considered in these lesions (9). Hence, many endocrinologists remain uneasy about managing large NIFTP $\geq 4 \mathrm{~cm}$ in size conservatively without postoperative RAI scanning and/or ablation.

In order to shed light on the prognosis of and appropriate treatment options for large NIFTP, a large cohort of 79 cases of NIFTP $\geq 4 \mathrm{~cm}$ in size from four tertiary hospitals was studied.

\section{Material and Methods}

\section{Study cohort}

After obtaining approval from the various Institutional Review Boards, the pathology databases of four tertiary hospitals (Sunnybrook Health Sciences Centre [SHSC], Tor- onto, Canada; Ospedale Maggiore, Bologna, Italy; Cornell University, New York, NY; and Memorial Sloan Kettering Cancer Center [MSKCC], New York, NY) were searched. The search periods and criteria were: SHSC 1999-2015, FVPTC and FA; Ospedale Maggiore 1995-2010, FA; Cornell University 2000-2014, FVPTC; and MSKCC 19822015, FVPTC. Each of the four pathologists (B.X., G.T., T.S., and R.G.) independently reviewed all the slides from each case emanating from his/her institution to confirm the diagnosis of NIFTP using the criteria proposed by Nikiforov et al. (3). In brief, NIFTP was diagnosed when all of the following criteria were met: (i) encapsulation or clear demarcation; (ii) exclusive/predominant follicular growth pattern lacking psammoma bodies and with $<1 \%$ true papillae and $30 \%$ solid growth pattern; (iii) nuclear atypia in the form of nuclear enlargement, nuclear membrane irregularity, and/or chromatin clearing with a nuclear score of 2-3; (iv) absence of invasion (vascular or capsular); (v) no tumor necrosis; and (vi) a mitotic index $<3$ per 10 high power fields $(400 \times$; Fig. 1). In regard to the scoring system developed in the original NIFTP paper (3), the nuclear features of the tumor were scored based on three criteria: (i) size and shape (nuclear enlargement, overlapping, and/or elongation), (ii) nuclear membrane irregularities (irregular contours, grooves, and/or pseudo-inclusions), and (iii) chromatin characteristics (chromatin clearing, margination of chromatin to membrane, and/or glassy nuclei). A three-point scoring scheme was developed, in which each class of nuclear features was assigned a score of 0 or 1 , yielding a range of scores from 0 to 3 . A diagnostic score of 2 or 3 was required for a diagnosis of NIFTP. The extent of PTC nuclei in the entire lesion was not studied, since the original NIFTP study did not require a specific minimal percentage of the tumor to demonstrate these nuclear features. Capsular and vascular invasion was diagnosed according to the Armed Forces Institute of $\mathrm{Pa}$ thology (AFIP) atlas on tumors of the thyroid gland (10). Capsular invasion was defined as complete penetration of the lesional capsule by a tumor bud. The presence of vascular invasion was noted only when such foci were present within or beyond the tumor capsule. Briefly, only when the invasive
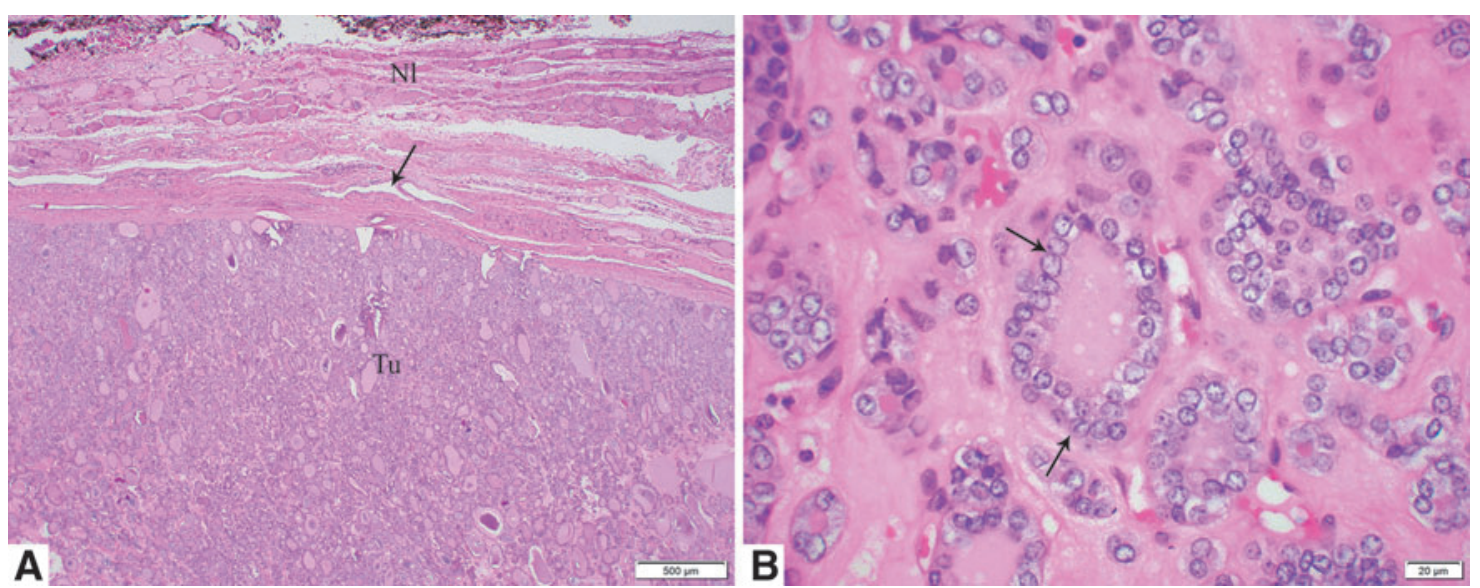

FIG. 1. Histology pictures of a $5.6 \mathrm{~cm}$ noninvasive follicular thyroid neoplasm with papillary-like nuclear features (NIFTP) treated by lobectomy without radioactive iodine therapy in a 65-year-old male patient. The patient was alive without evidence of disease 13 years and 4 months after diagnosis. Microscopic pictures of the tumor in (A) at low power ( $40 \times)$ show an encapsulated follicular noninvasive neoplasm (arrow, tumor capsule; tu, tumor; N1, normal adjacent thyroid). In (B), at high power $(600 \times)$, NIFTP is composed of follicles lined by enlarged, clear, irregular, overlapping nuclei with grooves (arrows). 
focus protruded into the lumen of the vessel in a polypoid manner covered by endothelial cells, or when it was attached to the vessel wall or associated with thrombus formation, was it considered true vascular invasion. Cases with separate foci of carcinoma (mostly papillary microcarcinomas) were excluded from the study. A total of 79 cases fulfilling the above criteria were included in the present study.

\section{Clinical review}

Each patient's chart was reviewed to record the following clinical parameters: age at diagnosis, sex, type of resection (total thyroidectomy vs. lobectomy/hemithyroidectomy), status of postoperative RAI ablation, duration of clinical FU, and clinical outcome.

\section{Statistics}

All statistical analyses were performed using IBM SPSS Statistics for Windows v22.0 (IBM Corp., Armonk, NY). The association between different clinicopathologic characteristics and RAI status was calculated using Fisher's exact test for categorical variables and a two-tailed Student's $t$-test for continuous variables. $p$-Values of $<0.05$ were considered to be statistically significant.

\section{Results}

Seventy-nine patients fulfilling the inclusion criteria were included in this study. Thirteen of these cases have been previously reported as NIFTP (3). The numbers of cases according to the institutions were: $\operatorname{MSKCC} N=56$; $\operatorname{SHSC} N=11$; Bologna University $N=7$; and Cornell University $N=5$. The clinicopathologic characteristics are summarized in Table 1. Large NIFTP were more frequently present in female patients, with a male to female ratio of $1: 1.8$. The median age at diagnosis was 49 years (range 22-81 years). The median size of the NIFTP was $4.5 \mathrm{~cm}$ (range $4.0-8.0 \mathrm{~cm}$ ). All tumors were confined to the thyroid and were resected completely with negative surgical margins during the initial surgery. There were no lymph node metastases at diagnosis in any of the patients, and none of the patients $(n=25)$ in whom nodal tissue was available for microscopic examination had positive findings.

The entire tumor capsule or the entire tumor was examined histologically in $50(63 \%)$ cases, while in the remaining $29(37 \%)$, the tumor was submitted representatively with a median of 2.1 blocks (range 0.5-4.2) per centimeter of tumor examined.

Among these 79 patients, $64(81 \%)$ had clinical FU available, with a median FU duration of 5.8 years $(M=7.3$ years; range 0.3-26.0 years). Sixty (76\%) had at least two years, and $49(62 \%)$ had at least four years of FU. Twenty-six $(33 \%)$ patients underwent thyroid lobectomy for their primary tumor, while the remaining patients were treated with total/subtotal thyroidectomy. Thirty-seven (47\%) did not receive postoperative RAI ablation. No recurrence or diseasespecific death was observed in the entire cohort, including all 32 patients with two or more years of FU who did not receive RAI therapy (median FU in this group of patients: 6.7 years; $M=8.6$ years). Among patients with four or more years of FU, all 25 individuals without RAI therapy did not recur, with a median FU of 11.2 years $(M=10.1$ years $)$.

In this cohort, it appeared that patients with a larger size of NIFTP were treated significantly more frequently with RAI
Table 1. Clinicopathologic Characteristics of Patients With LARge NIFTP ${ }^{\mathrm{a}}$

All cases $(\mathrm{n}=79)$

Sex

Female

Male

Age, years, median (range)

Size, cm, median (range)

Sampling of NIFTP

Entirely or entire capsule

Representative

Blocks sampled per $\mathrm{cm}$ of tumor

if only representatively

sampled, median (range)

Sampling and status of lymph nodes

Not sampled

Benign lymph node(s)

$25-32 \%$

Surgical procedure

Lobectomy

Total/subtotal thyroidectomy

Postoperative RAI ablation

Not available

No RAI

RAI

FU duration, years, median, mean (range)

Disease status at last FU

Not available $\quad 15 \quad 19 \%$

NED $64 \quad 81 \%$

Patients with large NIFTP and at least 2-year FU $(\mathrm{n}=60)$

RAI

Not available $112 \%$

No RAI $\quad 32 \quad 53 \%$

$\begin{array}{lll}\text { RAI } & 27 & 45 \%\end{array}$

Surgical procedure

Lobectomy

Total/subtotal thyroidectomy

$17 \quad 28 \%$

$43 \quad 72 \%$

FU duration, years, median.

mean (range)

Disease status at last FU

NED

$60 \quad 100 \%$

Patients with large NIFTP and at least 4-year FU $(\mathrm{n}=49)$

RAI

Not available $\quad 1 \quad 2 \%$

No RAI $\quad 25 \quad 51 \%$

RAI $23 \quad 47 \%$

Surgical procedure

Lobectomy $\quad 15 \quad 31 \%$

Total/subtotal thyroidectomy $34 \quad 69 \%$

FU duration, years, median, $\quad 7.2,8.8$ (4.0-26.0) mean (range)

Disease status at last FU

NED

49

$100 \%$

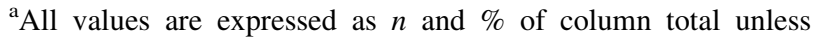
otherwise specified.

NIFTP, noninvasive follicular thyroid neoplasm with papillarylike nuclear features; RAI, radioactive iodine; FU, follow-up; NED, no evidence of disease.

( $p=0.001 ;$ Table 2). The median size of the NIFTP in the group subjected to RAI was $5.0 \mathrm{~cm}$ compared with $4.2 \mathrm{~cm}$ in those patients who did not receive RAI. Other parameters, for example age and sex, did not have a significant impact on RAI administration in this cohort. As total thyroidectomy 
Table 2. RaI Status in Patients with Large NifTP and At Least Two- or Four-Year FU

\begin{tabular}{|c|c|c|c|c|c|}
\hline & \multicolumn{2}{|c|}{ No RAI } & \multicolumn{2}{|c|}{$R A I$} & $\mathrm{p}$-Value \\
\hline \multicolumn{6}{|l|}{ Patients with at least two-year FU $(\mathrm{n}=59)$} \\
\hline$n$ & \multicolumn{2}{|l|}{32} & \multicolumn{2}{|l|}{27} & \\
\hline \multicolumn{6}{|l|}{ Sex } \\
\hline Female & 23 & $72 \%$ & 17 & $63 \%$ & \multirow[t]{2}{*}{0.579} \\
\hline Male & 9 & $28 \%$ & 10 & $37 \%$ & \\
\hline \multicolumn{6}{|l|}{ Surgical procedure } \\
\hline Lobectomy & 17 & $53 \%$ & 0 & $0 \%$ & \multirow[t]{2}{*}{$<0.001$} \\
\hline Total/subtotal thyroidectomy & 15 & $47 \%$ & 27 & $100 \%$ & \\
\hline \multicolumn{6}{|l|}{ Sampling of NIFTP } \\
\hline Entirely/entire capsule & 20 & $63 \%$ & 14 & $52 \%$ & \multirow{2}{*}{0.440} \\
\hline Representative & 12 & $38 \%$ & 13 & $48 \%$ & \\
\hline \multicolumn{6}{|l|}{ Sampling and status of lymph nodes } \\
\hline Not sampled & 24 & $75 \%$ & 18 & $67 \%$ & 0.569 \\
\hline Benign lymph node(s) & 8 & $25 \%$ & 9 & $33 \%$ & \\
\hline Age, years, median (range) & \multicolumn{2}{|c|}{$50(27-76)$} & \multicolumn{2}{|c|}{$49(24-64)$} & 0.517 \\
\hline Size, $\mathrm{cm}$, median (range) & \multicolumn{2}{|c|}{$4.2(4.0-5.8)$} & \multicolumn{2}{|c|}{$5.0(4.0-7.5)$} & 0.001 \\
\hline FU duration, years, median, mean (range) & \multirow{2}{*}{\multicolumn{2}{|c|}{$\begin{array}{c}7.5,7.5(2.4-20.5) \\
2.2(0.8-4.1)\end{array}$}} & \multirow{2}{*}{\multicolumn{2}{|c|}{$\begin{array}{c}5.8,6.8(2.0-26.0) \\
2.0(0.5-4.2)\end{array}$}} & 0.181 \\
\hline $\begin{array}{l}\text { Blocks sampled per } \mathrm{cm} \text { of tumor if only } \\
\text { representatively sampled, median (range) }\end{array}$ & & & & & 0.614 \\
\hline \multicolumn{6}{|l|}{ Patients with at least four-year $F U(n=48)$} \\
\hline$n$ & 25 & $100 \%$ & 23 & $100 \%$ & \\
\hline \multicolumn{6}{|l|}{ Surgical procedure } \\
\hline Lobectomy & 15 & $60 \%$ & 0 & $0 \%$ & $<0.001$ \\
\hline Total/subtotal thyroidectomy & 10 & $40 \%$ & 23 & $100 \%$ & \\
\hline Size, $\mathrm{cm}$, median (range) & \multicolumn{2}{|c|}{$4.2(4.0-5.6)$} & \multicolumn{2}{|c|}{$5.0(4.0-7.5)$} & 0.001 \\
\hline
\end{tabular}

${ }^{a}$ All values are expressed as $n$ and \% of column total unless otherwise specified.

b $p$-Values are calculated using Fisher's exact test for categorical variables and a two-tailed Student's $t$-test for continuous variables.

was a prerequisite for postoperative RAI, it was not surprising to detect a significant correlation between the type of surgical procedure and RAI ablation $(p<0.001)$.

\section{Discussion}

Encapsulated/well-demarcated noninvasive FVPTC has an estimated annual occurrence of 45,000 worldwide and was considered a cancer for the past three decades (11). It is not until recently that compelling molecular evidence and clinical outcome data have demonstrated that noninvasive encapsulated FVPTC follows a highly indolent clinical course with negligible risk of recurrence, and it carries a molecular signature resembling FA/follicular carcinoma with $R A S$ mutations as the most frequently encountered alteration $(3,5-$ $7,12)$. In 2016, the "group for the re-examination of the encapsulated follicular variant of papillary thyroid cancer" studied 106 patients with noninvasive encapsulated FVPTC with at least 10 years of FU and provided an in-depth analysis of the morphological, molecular, and clinical findings of these lesions (3). Based on the negligible recurrence risk of this lesion, the group proposed a nomenclature change to NIFTP, eliminating the word "carcinoma" (3). This modification in the diagnostic terminology aimed at reducing overtreatment and eliminating the social stigma associated with a cancer diagnosis. Nevertheless, many clinicians remain uncomfortable treating a patient with large NIFTP $\geq 4 \mathrm{~cm}$ in size conservatively, as these lesions used to be staged as T3 and stage III (if $>45$ years old) using the AJCC staging manual 7th edition (8). This discomfort is confirmed by data from the present study in which patients with larger tumors were treated significantly more frequently with RAI.
To date, no studies have focused on the prognosis of large $(\geq 4 \mathrm{~cm})$ NIFTP, previously termed noninvasive encapsulated follicular variant of PTC.

None of the patients in the present cohort harboring large NIFTP had lymph node metastasis or disease recurrence, including those patients treated with surgery alone without postoperative RAI. The data provide additional confirmatory evidence to previous reports demonstrating the highly indolent nature of NIFTP in general. Although not centered on large NIFTP, a few of these previous publications included some large NIFTP (up to $9 \mathrm{~cm}$ ) that did not recur, which is in line with the findings of the current series $(3,13,14)$.

In the English language literature, only 2/388 (0.5\%) welldocumented, well-circumscribed/encapsulated noninvasive FVPTC (now renamed as NIFTP) recurred $(13,15-21)$. Of note, the tumor was present at the margin in one of the relapsing cases, and the noninvasive nature of the tumor is questionable in the second case (3). Even if these two relapsing tumors were included, the recurrence rate of these tumors still remains extremely low $(<0.5 \%)$ based on the total number of patients published and the current series. In order to have a pure population of NIFTP, four endocrine pathologists with special interests in thyroid neoplasia reviewed these tumors, applying the stringent criteria advocated for the diagnosis of this entity (3). A meticulous histopathologic examination is of paramount importance, since a deviation from these criteria may affect outcomes. For example, the presence of a minor but significant amount of papillae formation $(>1 \%)$ may increase the risk of lymph node metastasis. It was previously reported that encapsulated carcinomas harboring $>1 \%$ papillae (encapsulated classical PTC) can give rise to lymph node metastasis, despite a total 
lack of invasion in $27 \%$ of cases (22). Evidently, the most crucial parameter for the diagnosis of NIFTP is the evaluation of capsular and vascular invasion. The definition of invasion can vary between pathologists and constitute a source of inter-observer variability. Therefore, the most widely utilized and validated definitions for capsular/vascular invasion were used. The latter are clearly described in the most recent authoritative AFIP atlas on tumors of the thyroid gland (10). Another requirement for an accurate assessment of invasion is a well-sampled tumor capsule. In the current series, the entire capsule was microscopically examined in $50(63 \%)$ of the tumors, while in the remaining $29(37 \%)$ cases, it was submitted representatively, with a median of 2.1 blocks per centimeter of tumor examined. This is clearly above the required one block of tumor capsule per centimeter of tumor recommended by the AFIP atlas on tumors of the thyroid gland (10). It is therefore thought that the present cases met all the required criteria for NIFTP, including adequate sampling. Indeed, in the original NIFTP paper, the authors stated that adequacy of tumor capsule microscopic examination is imperative for the diagnosis of NIFTP (3). They further commented that "adequacy of tumor capsule sampling has not been discussed in the literature to date with respect to FVPTC." They and the current authors believe that sampling of the entire tumor capsule is preferable. Nikiforov et al. concluded by saying that "NIFTP should undergo extensive review of the tumor capsule interface to exclude invasion" (3) but stay short of requiring examination of the entire tumor capsule in order to diagnose NIFTP. To understand the biologic behavior of uninodular large NIFTP independently from the presence of separate carcinomas in the thyroid, all cases harboring additional foci of carcinoma were excluded. In view of that design, how often NIFTP is part of a multicentric tumor process could not be assessed. In regard to FU, there was a reliance on structural rather than biochemical recurrence to assess a patient's disease status. This was in part due to the fact that some archived cases were not evaluated recently and did not have adequate serum thyroglobulin data. Although a long FU time was not available in all cases, this study comprised 25 patients treated by surgery without RAI therapy who did not recur, with a median FU of 11.2 years. These data strongly suggest that large NIFTP have an extremely low relapse rate. Indeed, most differentiated thyroid carcinomas recur during the first decade (23), although late recurrences and distant spread have been documented (24). The lack of recurrence in these patients without adjuvant RAI therapy suggests that they could be spared completion thyroidectomy and RAI, despite the large size of their tumors. These patients could then avoid the potential complications of total thyroidectomy, eventual side effects of RAI therapy, and the financial costs associated with these therapeutic modalities $(25,26)$. The indolent behavior of these large NIFTP further reinforces the fact that invasion rather than nuclear features or tumor size drives outcomes in encapsulated follicular-patterned tumors (18). The lack of nodal metastasis at presentation in all cases, including those with microscopically examined lymph nodes, is also consistent with the fact that these are mainly $R A S$ - as well as $P A X 8$ $P P A R G$-driven neoplasms and hence have a behavior very similar to FAs (12). Indeed, encapsulated $R A S$-driven follicular cell-derived thyroid tumors (e.g., follicular carcinomas, NIFTP, encapsulated FVPTC with invasion) do not usually spread to lymph nodes in sharp contrast to $B R A F$ mutated classical PTC $(10,22)$.

In conclusion, this study suggests that large NIFTP have an extremely low risk of recurrence, even when treated conservatively without RAI therapy. Conservative surgical treatment alone appears to be adequate for large NIFTP. Future long-term follow-up studies on large NIFTP will help confirm these findings and further reassure patients and their clinicians.

\section{Acknowledgments}

Research reported in this publication was supported in part by the Cancer Center Support Grant of the National Institutes of Health/National Cancer Institute under award number P30CA008748. The content is solely the responsibility of the authors and does not necessarily represent the official views of the National Institutes of Health.

\section{Author Disclosure Statement}

No competing financial interests exist for all contributory authors.

\section{References}

1. Siegel R, Ma J, Zou Z, Jemal A 2014 Cancer statistics, 2014. CA Cancer J Clin 64:9-29.

2. Jung CK, Little MP, Lubin JH, Brenner AV, Wells SA Jr, Sigurdson AJ, Nikiforov YE 2014 The increase in thyroid cancer incidence during the last four decades is accompanied by a high frequency of $B R A F$ mutations and a sharp increase in $R A S$ mutations. J Clin Endocrinol Metab 99:E276-285.

3. Nikiforov YE, Seethala RR, Tallini G, Baloch ZW, Basolo F, Thompson LD, Barletta JA, Wenig BM, Al Ghuzlan A, Kakudo K, Giordano TJ, Alves VA, Khanafshar E, Asa SL, El-Naggar AK, Gooding WE, Hodak SP, Lloyd RV, Maytal G, Mete O, Nikiforova MN, Nose V, Papotti M, Poller DN, Sadow PM, Tischler AS, Tuttle RM, Wall KB, LiVolsi VA, Randolph GW, Ghossein RA 2016 Nomenclature revision for encapsulated follicular variant of papillary thyroid carcinoma: a paradigm shift to reduce overtreatment of indolent tumors. JAMA Oncol 2:1023-1029.

4. DeLellis RA, Lloyd RV, Heitz PU, Eng C 2004 Pathology and Genetics of Tumours of the Endocrine Organs. IARC Press, Lyon, France.

5. Agrawal N, Akbani R, Aksoy BA, Ally A, Arachchi H, Asa SL, Auman JT, Balasundaram M, Balu S, Baylin SB, Behera M, Bernard B, Beroukhim R, Bishop JA, Black AD, Bodenheimer T, Boice L, Bootwalla MS, Bowen J, Bowlby R, Bristow CA, Brookens R, Brooks D, Bryant R, Buda E, Butterfield YSN, Carling T, Carlsen R, Carter SL, Carty SE, Chan TA, Chen AY, AD Cherniack, Cheung D, Chin L, Cho J, Chu A, Chuah E, Cibulskis K, Ciriello G, Clarke A, Clayman GL, Cope L, Copland J, Covington K, Danilova L, Davidsen T, Demchok JA, DiCara D, Dhalla N, Dhir R, Dookran SS, Dresdner G, Eldridge J, Eley G, El-Naggar AK, Eng S, Fagin JA, Fennell T, Ferris RL, Fisher S, Frazer S, Frick J, Gabriel SB, Ganly I, Gao J, Garraway LA, Gastier-Foster JM, Getz G, Gehlenborg N, Ghossein R, Gibbs RA, Giordano TJ, Gomez-Hernandez K, Grimsby J, Gross B, Guin R, Hadjipanayis A, Harper HA, Hayes DN, Heiman DI, Herman JG, Hoadley KA, Hofree M, Holt RA, Hoyle AP, Huang SW, Huang M, Hutter CM, Ideker T, Iype L, Jacobsen A, Jefferys SR, Jones CD, Jones SJM, Kasaian K, Kebebew E, Khuri FR, Kim J, Kramer R, 
Kreisberg R, Kucherlapati R, Kwiatkowski DJ, Ladanyi M, Lai PH, Laird PW, Lander E, Lawrence MS, Lee D, Lee E, Lee S, Lee W, Leraas KM, Lichtenberg TM, Lichtenstein L, Lin P, Ling S, Liu J, Liu W, Liu Y, LiVolsi VA, Lu Y, Ma Y, Mahadeshwar HS, Marra MA, Mayo M, McFadden DG, Meng S, Meyerson M, Mieczkowski PA, Miller M, Mills G, Moore RA, Mose LE, Mungall AJ, Murray BA, Nikiforov YE, Noble MS, Ojesina AI, Owonikoko TK, Ozenberger BA, Pantazi A, Parfenov M, Park PJ, Parker JS, Paull EO, Pedamallu CS, Perou CM, Prins JF, Protopopov A, Ramalingam SS, Ramirez NC, Ramirez R, Raphael BJ, Rathmell WK, Ren X, Reynolds SM, Rheinbay E, Ringel MD, Rivera M, Roach J, Robertson AG, Rosenberg MW, Rosenthall M, Sadeghi S, Saksena G, Sander C, Santoso N, Schein JE, Schultz N, Schumacher SE, Seethala RR, Seidman J, Senbabaoglu Y, Seth S, Sharpe S, Mills Shaw KR, Shen JP, Shen R, Sherman S, Sheth M, Shi Y, Shmulevich I, Sica GL, Simons JV, Sipahimalani P, Smallridge RC, Sofia HJ, Soloway MG, Song X, Sougnez C, Stewart C, Stojanov P, Stuart JM, Tabak B, Tam A, Tan D, Tang J, Tarnuzzer R, Taylor BS, Thiessen N, Thorne L, Thorsson V, Tuttle RM, Umbricht CB, Van Den Berg DJ, Vandin F, Veluvolu U, Verhaak RGW, Vinco M, Voet D, Walter V, Wang Z, Waring S, Weinberger PM, Weinstein JN, Weisenberger DJ, Wheeler D, Wilkerson MD, Wilson J, Williams M, Winer DA, Wise L, Wu J, Xi L, Xu AW, Yang L, Yang L, Zack TI, Zeiger MA, Zeng D, Zenklusen JC, Zhao N, Zhang H, Zhang J, Zhang J, Zhang W, Zmuda E, Zou L 2014 Integrated genomic characterization of papillary thyroid carcinoma. Cell 159:676-690.

6. Liu J, Singh B, Tallini G, Carlson DL, Katabi N, Shaha A, Tuttle RM, Ghossein RA 2006 Follicular variant of papillary thyroid carcinoma: a clinicopathologic study of a problematic entity. Cancer 107:1255-1264.

7. Zhu Z, Gandhi M, Nikiforova MN, Fischer AH, Nikiforov YE 2003 Molecular profile and clinical-pathologic features of the follicular variant of papillary thyroid carcinoma. An unusually high prevalence of ras mutations. Am J Clin Pathol 120:71-77.

8. Edge SB, Byrd DR, Compton CC, Fritz AG, Greene FL, Torotti A 2010 AJCC Cancer Staging Manual. Seventh edition. Springer-Verlag, New York, NY.

9. Haugen BRM, Alexander EK, Bible KC, Doherty G, Mandel SJ, Nikiforov YE, Pacini F, Randolph G, Sawka A, Schlumberger M, Schuff KG, Sherman SI, Sosa JA, Steward D, Tuttle RMM, Wartofsky L 20162015 American Thyroid Association management guidelines for adult patients with thyroid nodules and differentiated thyroid cancer. Thyroid 26:1-133.

10. Rosai J, DeLellis RA, Carcangiu ML, Frable WJ, Tallini G 2015 Tumor of the Thyroid and Parathyroid Gland (AFIP Atlas of Tumor Pathology Series 4). American Registry of Pathology Press, Silver Spring, MD.

11. Tallini G, Tuttle RM, Ghossein RA 2016 The history of the follicular variant of papillary thyroid carcinoma. J Clin Endocrinol Metab [Epub ahead of print]; DOI: 10.1210/jc .2016-2976.

12. Rivera M, Ricarte-Filho J, Knauf J, Shaha A, Tuttle M, Fagin JA, Ghossein RA 2010 Molecular genotyping of papillary thyroid carcinoma follicular variant according to its histological subtypes (encapsulated vs infiltrative) reveals distinct $B R A F$ and RAS mutation patterns. Mod Pathol 23:1191-1200.

13. Howitt BE, Paulson VA, Barletta JA 2015 Absence of BRAF V600E in non-infiltrative, non-invasive follicular variant of papillary thyroid carcinoma. Histopathology 67: $579-582$.
14. Rosario PW, Mourao GF, Nunes MB, Nunes MS, Calsolari MR 2016 Noninvasive follicular thyroid neoplasm with papillarylike nuclear features. Endocr Relat Cancer 23:893-897.

15. Thompson LD 2016 Ninety-four cases of encapsulated follicular variant of papillary thyroid carcinoma: a name change to noninvasive follicular thyroid neoplasm with papillary-like nuclear features would help prevent overtreatment. Mod Pathol 29:698-707.

16. Piana S, Frasoldati A, Di Felice E, Gardini G, Tallini G, Rosai J 2010 Encapsulated well-differentiated follicularpatterned thyroid carcinomas do not play a significant role in the fatality rates from thyroid carcinoma. Am J Surg Pathol 34:868-872.

17. Vivero M, Kraft S, Barletta JA 2013 Risk stratification of follicular variant of papillary thyroid carcinoma. Thyroid 23: 273-279.

18. Ganly I, Wang L, Tuttle RM, Katabi N, Ceballos GA, Harach HR, Ghossein R 2015 Invasion rather than nuclear features correlates with outcome in encapsulated follicular tumors: further evidence for the reclassification of the encapsulated papillary thyroid carcinoma follicular variant. Hum Pathol 46:657-664.

19. Rosario PW, Penna GC, Calsolari MR 2014 Noninvasive encapsulated follicular variant of papillary thyroid carcinoma: is lobectomy sufficient for tumours $\geq 1 \mathrm{~cm}$ ? Clin Endocrinol (Oxf) 81:630-632.

20. Liu Z, Zhou G, Nakamura M, Koike E, Li Y, Ozaki T, Mori I, Taniguchi E, Kakudo K 2011 Encapsulated follicular thyroid tumor with equivocal nuclear changes, so-called well-differentiated tumor of uncertain malignant potential: a morphological, immunohistochemical, and molecular appraisal. Cancer Sci 102:288-294.

21. Baloch ZW, LiVolsi VA 2000 Encapsulated follicular variant of papillary thyroid carcinoma with bone metastases. Mod Pathol 13:861-865.

22. Rivera M, Tuttle RM, Patel S, Shaha A, Shah JP, Ghossein RA 2009 Encapsulated papillary thyroid carcinoma: a clinico-pathologic study of 106 cases with emphasis on its morphologic subtypes (histologic growth pattern). Thyroid 19:119-127.

23. Mazzaferri EL, Jhiang SM 1994 Long-term impact of initial surgical and medical therapy on papillary and follicular thyroid cancer. Am J Med 97:418-428.

24. Nwatsock JF, Taieb D, Zok FD, Mundler O 2012 Late recurrences of thyroid carcinoma 24 years after a complete remission: when monitoring should be stopped? World J Nucl Med 11:42-43.

25. Hauch A, Al-Qurayshi Z, Randolph G, Kandil E 2014 Total thyroidectomy is associated with increased risk of complications for low- and high-volume surgeons. Ann Surg Oncol 21:3844-3852.

26. Iyer NG, Morris LG, Tuttle RM, Shaha AR, Ganly I 2011 Rising incidence of second cancers in patients with lowrisk (T1N0) thyroid cancer who receive radioactive iodine therapy. Cancer 117:4439-4446.

Address correspondence to: Ronald Ghossein, MD Department of Pathology Memorial Sloan-Kettering Cancer Center 1275 York Avenue New York, NY 10065

E-mail: ghosseir@mskcc.org 